\title{
Trajectories of adherence to mood stabilizers in patients with bipolar disorder
}

\author{
M. Bauer ${ }^{1 *}$, T. Glenn², M. Alda ${ }^{3}$, R. Bauer ${ }^{1}$, P. Grof ${ }^{4}$, W. Marsh ${ }^{5}$, S. Monteith ${ }^{6}$, R. Munoz ${ }^{7}$, N. Rasgon, \\ K. Sagduyu ${ }^{9 \wedge}$ and P. C. Whybrow ${ }^{10}$
}

\begin{abstract}
Background: Nonadherence with mood stabilizers is a major problem that negatively impacts the course of bipolar disorder. Medication adherence is a complex individual behavior, and adherence rates often change over time. This study asked if distinct classes of adherence trajectories with mood stabilizers over time could be found, and if so, which patient characteristics were associated with the classes.

Methods: This analysis was based on 12 weeks of daily self-reported data from 273 patients with bipolar 1 or II disorder using ChronoRecord computer software. All patients were taking at least one mood stabilizer. The latent class mixed model was used to detect trajectories of adherence based on 12 weekly calculated adherence datapoints per patient.

Results: Two distinct trajectory classes were found: an adherent class (210 patients; $77 \%)$ and a less adherent class (63 patients; $23 \%)$. The characteristics associated with the less adherent class were: more time not euthymic $(p<0.001)$ and female gender $(p=0.016)$. No other demographic associations were found.

Conclusion: In a sample of motivated patients who complete daily mood charting, about one quarter were in the less adherent class. Even patients who actively participate in their care, such as by daily mood charting, may be nonadherent. Demographic characteristics may not be useful in assessing individual adherence. Future research on longitudinal adherence patterns in bipolar disorder is needed.
\end{abstract}

\section{Introduction}

Mood stabilizers are a fundamental treatment for both acute episodes of bipolar disorder and the prevention of future episodes. Patient nonadherence is an important contributor to medication nonresponse (Osterberg and Blaschke 2005), and nonadherence with mood stabilizers may negatively impact every aspect of bipolar disorder. Poor medication adherence is associated with an increase in relapses (Gutiérrez-Rojas et al. 2010; Franks et al. 2008), suicide and suicide attempts (Gonzalez-Pinto et al. 2006; Pompili et al. 2009), emergency room visits, hospitalizations, involuntary hospitalizations, healthcare

\footnotetext{
*Correspondence: michael.bauer@uniklinikum-dresden.de

$\wedge$ Deceased

1 Department of Psychiatry and Psychotherapy, Medical Faculty, University Hospital Carl Gustav Carus, Technische Universität Dresden, Fetscherstr. 74, 01307 Dresden, Germany

Full list of author information is available at the end of the article
}

costs (Svarstad et al. 2001; Gianfrancesco et al. 2008; Hong et al. 2011; Eaddy et al. 2005; Hassan and Lage 2009; Schuepbach et al. 2008), homelessness (Copeland et al. 2009), and involvement with the criminal justice system (Robertson et al. 2014). The harm from medication nonadherence in bipolar disorder is considerable to both individual patients and society.

Medication adherence refers to the extent to which patients follow the medication regimen prescribed by their physician, often defined as taking $\geq 80 \%$ of the prescribed doses (Osterberg and Blaschke 2005). Medication adherence involves three phases: initiation of treatment, implementation or following the dosing regimen, and persistence with treatment (Vrijens et al. 2012; Gellad et al. 2017). Diverse factors and behaviors influence each phase including patient attitudes towards medication, clinical symptoms, adverse reactions, regimen complexity, health literacy, substance 
misuse, medication costs and forgetfulness (Jawad et al. 2018; García et al. 2016; Levin et al. 2016; Fredericksen et al. 2018). An adherence rate is difficult to measure, and will vary with the definition, methodology, adherence phase, study design and study population (Sajatovic et al. 2010; Levin et al. 2016). Less than half of patients with bipolar disorder are estimated to be fully adherent (García et al. 2016; Levin et al. 2016; Scott and Pope 2002). For most patients with bipolar disorder, adherence is partial or intermittent, and changes over time (Scott and Pope 2002; Jawad et al. 2018). Sometimes patients take all the prescribed doses, sometimes a partial dose, and sometimes none for one or all drugs in the medication regimen.

The most frequent way that psychiatrists evaluate medication adherence in bipolar disorder is to ask the patient (Vieta et al. 2012). However, estimates are often incorrect and optimistic (Stephenson et al. 2012; Baldessarini et al. 2008; Lopez et al. 2017; De las Cuevas et al. 2013). Although physicians frequently adjust medications at visits for bipolar disorder (Hodgkin et al. 2018), it is challenging to differentiate non- or inadequate adherence from nonresponse (Velligan et al. 2009). A lack of recognition of patient nonadherence may lead to higher dosages, medication switches and increasingly complex medication regimens, which may further reduce adherence (Baldessarini et al. 2008; Eaddy et al. 2005; Velligan et al. 2009; Colom et al. 2005).

More information to help assess adherence in patients with bipolar disorder is needed. Adherence studies generally use conventional longitudinal modeling approaches that assume the individuals in a sample come from a homogeneous population, the outcome of interest has a single growth trajectory, and any defined covariates influence each individual in the same way (Jung and Wickrama 2008; Proust-Lima et al. 2017). In contrast, trajectory analysis accommodates a heterogeneous population, and allows the detection of subgroups or latent classes within a sample that have different trajectories of change over time for an outcome of interest (Nagin and Odgers 2010; Lennon et al. 2018; Jung and Wickrama 2008). Trajectory analysis was previously used to assess medication adherence for several chronic conditions (Greenley et al. 2015; de Vries McClintock et al. 2016; Hommel et al. 2017; Blalock et al. 2019). Based on 12 weeks of daily self-reported data from patients with bipolar disorder, the purpose of this study was twofold: (1) to determine whether distinct classes of adherence trajectories could be identified for patients taking mood stabilizers, and (2) if trajectory classes were present, to detect associations with patient characteristics.

\section{Methods}

All data were from outpatients with a diagnosis of bipolar disorder by DSM-IV or DSM- 5 criteria that was made by the prescribing psychiatrist during a clinical interview. All participants volunteered, were age 18 years or older, and provided informed written consent. The participants were recruited from a university mood clinic or private practice and received treatment as usual throughout the study. The participants agreed to record medications, mood and sleep daily using computer software in their native language (ChronoRecord). Demographic variables were obtained from the patient by the clinician at the time of enrollment. The demographic characteristics of patients who use ChronoRecord are similar to that for patients in other studies of bipolar disorder (Bauer et al. 2012). Patients were included in this analysis if they had a diagnosis of bipolar I or bipolar II disorder, returned at least 12 weeks of data (84 days), and were taking at least one mood stabilizer during the 12 weeks. Although arbitrary, 12 weeks of data provides sufficient time for adherence analysis, and includes patients that are comfortable with and willing to use ChronoRecord. Data used in this analysis were collected between 2000 and 2016. The ChronoRecord database was previously used for a variety of published analyses. Active collection of ChronoRecord data is ongoing.

\section{Daily data entry}

Patients entered mood, sleep, medications taken and life events daily, and weight weekly into ChronoRecord software (Bauer et al. 2004, 2008). All patients received about a half hour of training in person or by phone before entering data. During training, a medication list was created by selecting from a list of psychotropic medications displayed by brand and generic name. The list includes every medication taken for bipolar disorder. For each selected medication, the pill strength was chosen from a list of available strengths. Every day, for each medication, the patient entered the total number of pills taken. Patients could enter partial pills $(1 / 4,1 / 2$, or $3 / 4)$ for tablets but not capsules. If a medication was not taken, the patient entered zero pills for that drug. The patient could modify the drugs taken throughout the study as needed, and a drug not included in the software list could be added by the patient. Data not entered on one day could be entered later. The software prevents entry for a future date, prevents modification of previously entered data, and requires confirmation for entry of a large number of pills for a drug.

To record mood, patients entered a single daily rating that best described the prior $24 \mathrm{~h}$ using a 100 -unit visual analog scale. During training, the scale was calibrated to 
the extremes of mania and depression the patient ever experienced. Based upon the validation studies (Bauer et al. 2004, 2008), a mood entry less than 40 was considered depression, 40-60 euthymia, and greater than 60 hypomania/mania. The range of depression varied between mild symptoms (an entry of 20-39) to moderate to severe symptoms (an entry of 0-19). The range of mania varied from hypomania (an entry of 61-80) to moderate to severe symptoms of mania (an entry of 81-100).

\section{Drugs analyzed}

The mood stabilizers considered were lithium, valproate, lamotrigine, carbamazepine, oxcarbazepine and second generation antipsychotics: aripiprazole, olanzapine, risperidone, quetiapine, ziprasidone, paliperidone, asenapine, lurasidone, and clozapine. For the analysis of total psychotropic drugs taken and the daily pill burden, the other drugs considered were antidepressants, benzodiazepines, typical antipsychotics, insomnia medications, and other anticonvulsants (topiramate, gabapentin, pregabalin, tiagabine, levetiracetam, zonisamide).

\section{Adherence}

All medication data were self-reported, so the prescribed dosage and medication changes were not known. For each patient, adherence was defined as taking at least one pill per day of each prescribed mood stabilizer. An entry of 0 pills or a missing day of data were treated as no pills taken. The adherence was calculated for each day, and then a weekly adherence rate was created for a total of 12 weekly datapoints per patient. For example to calculate a weekly rate, consider a patient taking 2 mood stabilizers. If the patient took at least one pill for drug A on 7 days, and took at least one pill for drug B on 6 days, adherence for that week would be $86 \%$ (adherent on 6 days $/ 7$ days $=86 \%$ ). A mood stabilizer that was discontinued by tapering but remained on the medication list was not included in the calculation. If patients returned more than 84 days of data, only the first 12 weeks of data were included to balance the contribution of each patient.

\section{Latent class trajectory modeling}

The latent class mixed model (LCMM), an extension of a standard mixed model, was used to identify the trajectory classes for adherence with mood stabilizers (Proust-Lima et al. 2017; Lennon et al. 2018). Instead of one adherence trajectory for the entire sample, the LCMM allows multiple trajectory classes. LCMM identifies the trajectory classes without predefined assumptions as to the number, size or trajectory pattern of the classes. With LCMM, each patient is included in only one class, and each class has a distinct trajectory based on a supplied trajectory function. The individuals within each trajectory class will be similar to each other, and different from individuals in other classes. The package "lcmm" in R software was used for model estimation (Proust-Lima et al. 2017), and "LCMM toolkit" (Lennon et al. 2018) package was used to verify results.

The analysis models were checked for between 1 and 5 trajectory classes based on a quadratic adherence trajectory function over the 12 weeks. Covariates were not included in the trajectory function, and the variancecovariance matrix was not constrained. The probability that each patient was a member of a class was calculated and all patients were classified according to the highest probability. Several measures were used to help select the optimal number of classes (van de Schoot et al. 2017; Lennon et al. 2018), including the lowest Bayesian Information Criteria (BIC), class size, and probabilities of class membership. The choice of preferred model also included concerns for parsimony and interpretability of results (Jung and Wickrama 2008). To verify the model estimates were not influenced by the initial values, a grid search was performed to confirm the model estimates reflected the best estimates.

For the selected number of classes, the patient characteristics within the classes were compared using Chisquared tests for categorical variables and ANOVA for continuous variables. Demographic characteristics for the entire sample were also determined. SPSS version 25 was used for all demographic calculations.

\section{Results}

There were 560 patients with bipolar disorder in the database of which 528 had a diagnosis of bipolar I or bipolar II disorder. Of the 528 patients, 483 were taking a mood stabilizer, and 273 returned $\geq 84$ days of data and were included in the analysis. The 273 patients included in the analysis resided in the US $(189,69 \%)$, Germany (38, $14 \%)$, Canada (27, 10\%), Australia (7, 3\%), Chile (4, 1\%), Austria (3,1\%), Poland (3,1\%), and the UK (2, 1\%). Of the 273 patients, 151 (55\%) were recruited at a university mood center, and 122 (45\%) from a private practice. Of the 273 patients, 173 (63.4\%) had bipolar I disorder and 100 (36.6\%) had bipolar II disorder. Of the 273 patients, $192(70.3 \%)$ were female and $81(29.7 \%)$ were male. The demographic characteristics of 273 patients are shown in Table 1 . The 273 patients took a total of $2.8 \pm 1.4$ psychiatric drugs daily, with a mean pill burden of $6.3 \pm 4.3$ as shown in Table 2.

\section{Latent classes}

A comparison of the models identified by LCMM for $1-5$ trajectory classes are shown in Table 3 . Although the BIC for the 3 -class model $(-2108)$ was slightly smaller than 
Table 1 Patient demographics $(\mathbf{N}=\mathbf{2 7 3})$

\begin{tabular}{|c|c|c|}
\hline Category & $\mathbf{N}$ & Percent \\
\hline \multicolumn{3}{|l|}{ Gender } \\
\hline Female & 192 & 70.3 \\
\hline Male & 81 & 29.7 \\
\hline \multicolumn{3}{|l|}{ Diagnosis } \\
\hline BPI & 173 & 63.4 \\
\hline $\mathrm{BP} \|$ & 100 & 36.6 \\
\hline \multicolumn{3}{|l|}{ Disabled } \\
\hline No & 175 & 73.5 \\
\hline Yes & 63 & 26.5 \\
\hline \multicolumn{3}{|l|}{ Working full time } \\
\hline No & 131 & 55.0 \\
\hline Yes & 107 & 45.0 \\
\hline \multicolumn{3}{|l|}{ Any college } \\
\hline No & 32 & 12.5 \\
\hline Yes & 224 & 87.5 \\
\hline \multicolumn{3}{|l|}{ College graduate } \\
\hline No & 115 & 44.9 \\
\hline Yes & 141 & 55.1 \\
\hline \multicolumn{3}{|l|}{ Married } \\
\hline No & 133 & 52.2 \\
\hline \multirow[t]{2}{*}{ Yes } & 122 & 47.8 \\
\hline & Mean & SD \\
\hline Hospitalizations $(N=248)$ & 2.8 & 4.51 \\
\hline Age of onset $(N=253)$ & 22.3 & 10.34 \\
\hline Age $(N=273)$ & 40.8 & 11.07 \\
\hline Years of illness $(N=253)$ & 18.8 & 12.12 \\
\hline Percent days depressed $(\mathrm{N}=273)$ & 20.5 & 22.3 \\
\hline $\begin{array}{l}\text { Percent days manic/hypomanic } \\
\qquad(\mathrm{N}=273)\end{array}$ & 8.4 & 11.8 \\
\hline Percent days euthymic $(\mathrm{N}=273)$ & 64.3 & 27.5 \\
\hline
\end{tabular}

Table 2 Patient medications ( $\mathbf{N}=\mathbf{2 7 3}$ )

\begin{tabular}{lcc}
\hline Medication & N & Percent \\
\hline Lamotrigine & 117 & 42.9 \\
Lithium & 97 & 35.5 \\
Valproate & 58 & 21.2 \\
Carbamazepine/oxcarbazepine & 34 & 12.5 \\
Any antipsychotic & 123 & 45.1 \\
Any antidepressant & 135 & 49.5 \\
Any benzodiazepine & 58 & 21.2 \\
Any insomnia medication & 18 & 6.6 \\
\hline & Mean & SD \\
\hline Total number of medications $^{\mathrm{a}}$ & 2.8 & 1.4 \\
Total pill burden $^{\mathrm{a}}$ & 6.3 & 4.3 \\
\hline
\end{tabular}

a Only psychiatric drugs for the 2-class model $(-2091)$, one of the classes in the 3 -class model had only 20 members (7\%), the probability of class membership was lower, and trajectories for two of the three classes overlapped, making the interpretation of results more difficult. Therefore the 2-class model was selected as the preferred model.

For the preferred model, the actual and predicted weekly adherence trajectory over the 12 weeks for the two classes is shown in Fig. 1. One class has consistently high adherence over the 12 weeks and is referred to as the adherent class, while the other class has consistently lower adherence and is referred to as the less adherent class. The adherent class includes 210 patients or $77 \%$ of the group, while the less adherent class includes 63 patients or $23 \%$ of the group. The trajectory of the less adherent class was also relatively stable over the 12 weeks.

Only two patient characteristics differed between the classes. The less adherent class spent a smaller percentage of days euthymic, and included more females, as shown in Table 4. There were no significant differences between the two classes in other demographics including age, age of onset, diagnosis, college graduate, marital status, employed full time, number of hospitalizations for bipolar disorder, years of illness, or if receiving government disability payment due to bipolar disorder. There were no significant differences in the total number of psychiatric medications, daily pill burden, specific mood stabilizer taken, or the use of any antidepressant, benzodiazepine, stimulant or insomnia medication. There were no significant differences between the classes in the percentage of days with depression, severe depression, mania/hypomania or mania. The smaller percentage of days euthymic in the less adherent class was due to a larger percentage of days with depressive symptoms in some patients, and to a larger percentage of days with manic/hypomanic symptoms in others.

The mean percent of days missing medication data for all 273 patients was $7.0 \% \pm 13.5$. The mean percent of days missing medication data was $2.2 \% \pm 3.4$ for the adherent class and $22.9 \% \pm 20.5$ for the less adherent class $(\mathrm{p}<0.001)$.

\section{Discussion}

This analysis detected two distinct patterns of adherence with taking mood stabilizers over 12 weeks-an adherent class and a less adherent class. About one quarter of the patients were in the less adherent class. Patients in the less adherent class spent significantly more time with symptoms (not euthymic). In prior research in bipolar disorder, affective morbidity including frequent or severe episodes, psychosis, rapid cycling, and longer standing 
Table 3 LCMM parameter estimates for 1 to 5 classes $(\mathbf{N}=273)$ using a Quadratic Trajectory Function

\begin{tabular}{|c|c|c|c|c|c|c|c|c|c|c|}
\hline $\mathrm{N}$ classes & $\begin{array}{l}\text { Maximum log } \\
\text { likelihood }\end{array}$ & $A I C^{a}$ & $\mathrm{BIC}^{\mathbf{b}}$ & Relative entropy & Class parameter & Class 1 & Class 2 & Class 3 & Class 4 & Class 5 \\
\hline 1 & 716.85 & -1419.69 & -1394.43 & & $\begin{array}{l}\mathrm{N} \\
\% \\
\text { APPA }^{\mathrm{C}}\end{array}$ & $\begin{array}{l}273 \\
100 \% \\
1.000\end{array}$ & & & & \\
\hline $2^{d}$ & 1076.39 & -2130.79 & -2091.09 & 0.878 & $\begin{array}{l}\mathrm{N} \\
\% \\
\text { APPA }\end{array}$ & $\begin{array}{l}210 \\
77 \% \\
0.971\end{array}$ & $\begin{array}{l}63 \\
23 \% \\
0.968\end{array}$ & & & \\
\hline 3 & 1095.99 & -2161.98 & -2107.84 & 0.889 & $\begin{array}{l}\mathrm{N} \\
\% \\
\text { APPA }\end{array}$ & $\begin{array}{l}20 \\
7 \% \\
0.965\end{array}$ & $\begin{array}{l}202 \\
74 \% \\
0.968\end{array}$ & $\begin{array}{l}51 \\
19 \% \\
0.905\end{array}$ & & \\
\hline 4 & 1095.99 & -2153.98 & -2085.40 & 0.549 & $\begin{array}{l}\mathrm{N} \\
\% \\
\text { APPA }\end{array}$ & $\begin{array}{l}20 \\
7 \% \\
0.965\end{array}$ & $\begin{array}{l}198 \\
73 \% \\
0.507\end{array}$ & $\begin{array}{l}0 \\
0 \% \\
0.000\end{array}$ & $\begin{array}{l}55 \\
20 \% \\
0.870\end{array}$ & \\
\hline 5 & 1095.99 & -2145.98 & -2062.97 & 0.428 & $\begin{array}{l}\mathrm{N} \\
\% \\
\text { APPA }\end{array}$ & $\begin{array}{l}20 \\
7 \% \\
0.965\end{array}$ & $\begin{array}{l}0 \\
0 \% \\
0.000\end{array}$ & $\begin{array}{l}0 \\
0 \% \\
0.000\end{array}$ & $\begin{array}{l}193 \\
71 \% \\
0.344\end{array}$ & $\begin{array}{l}60 \\
22 \% \\
0.824\end{array}$ \\
\hline
\end{tabular}

Trajectory function was weekly adherence $=a_{0}+a_{1}{ }^{*}$ week $+a_{2}{ }^{*}$ week $^{2}$. No covariates were included

a Akaike Information Criterion

b Bayesian Information Criterion

c Average posterior probability of assignment

d Preferred model

illness were associated with nonadherence (Leclerc et al. 2013; Greene et al. 2018; Baldessarini et al. 2008; Levin et al. 2016; García et al. 2016). Symptoms that may be most severe during episodes, such as impulsivity (Swann et al. 2008) or lack of insight (Dell'Osso et al. 2002), were also associated with poor adherence (Leclerc et al. 2013, García et al. 2016; Pompili et al. 2009; Belzeaux et al. 2015). Other symptoms such as chaotic lifestyles, loss of daily routine, circadian disruption of sleep-wake cycles, and a preference for nighttime activities may make it harder to adhere with medication regimens (Frank et al. 2000; Melo et al. 2017).

Female gender was also associated with the less adherent class in this study. Although poorer adherence in females with bipolar disorder was reported previously (Kessing et al. 2007; Gianfrancesco et al. 2006; Belzeaux et al. 2013; Murru et al. 2013), review articles show contradictory results for a link between gender and adherence in bipolar disorder: no difference (Colom et al. 2005; Jawad et al. 2018; Greene et al. 2018), inconsistent (Levin et al. 2016), and males more associated with nonadherence (Pompili et al. 2009; Leclerc et al. 2013). In the European Social Survey of 45,700 participants from 24 countries, females were more likely to be nonadherent than males (Stavropoulou 2011). In a study in Japan, females with depression were more likely to hide information related to medication adherence (Sawada et al. 2012). However, the reasons for females being associated with the poor adherence class in this study are unknown.
Other demographic characteristics associated with nonadherence in bipolar disorder in prior research were not significant in this study, including less education, younger age, younger age of onset, and a marital status of single (Leclerc et al. 2013; Levin et al. 2016). Adherence involves a wide range of factors related to the individual, culture, language and communication, disease, drugs, physician, and healthcare system (Leclerc et al. 2013, Pompili et al. 2009; McQuaid and Landier 2018). The routinely collected demographic characteristics may not be associated with adherence, as found in non-psychiatric conditions (Franklin et al. 2016; Steiner et al. 2009) including studies using latent trajectory models (Blalock et al. 2019; de Vries McClintock et al. 2016). Additionally, when significant, the relation between adherence and demographic characteristics is usually weak, providing little practical assistance in discriminating between adherent and nonadherent patients (Steiner et al. 2009; Osterberg and Blaschke 2005). The difficulty in inferring individual adherence based on demographics suggests that self-reported measures may be helpful in clinical settings, and a variety of paper and automated tools are available (Steiner 2012; Stirratt et al. 2015). Review articles report moderate to high correlation between self-reported adherence questionnaires and diaries and electronic monitoring (Monnette et al. 2018; Garber et al. 2004; Shi et al. 2010). While all approaches to measure adherence have strengths and weaknesses (Sajatovic et al. 2010; Lehmann et al. 2014; Levin et al. 2015; Di Matteo 2004), good agreement was found between self-reported 


\section{Mood Stabalizer Adherence By Week For Each Class}

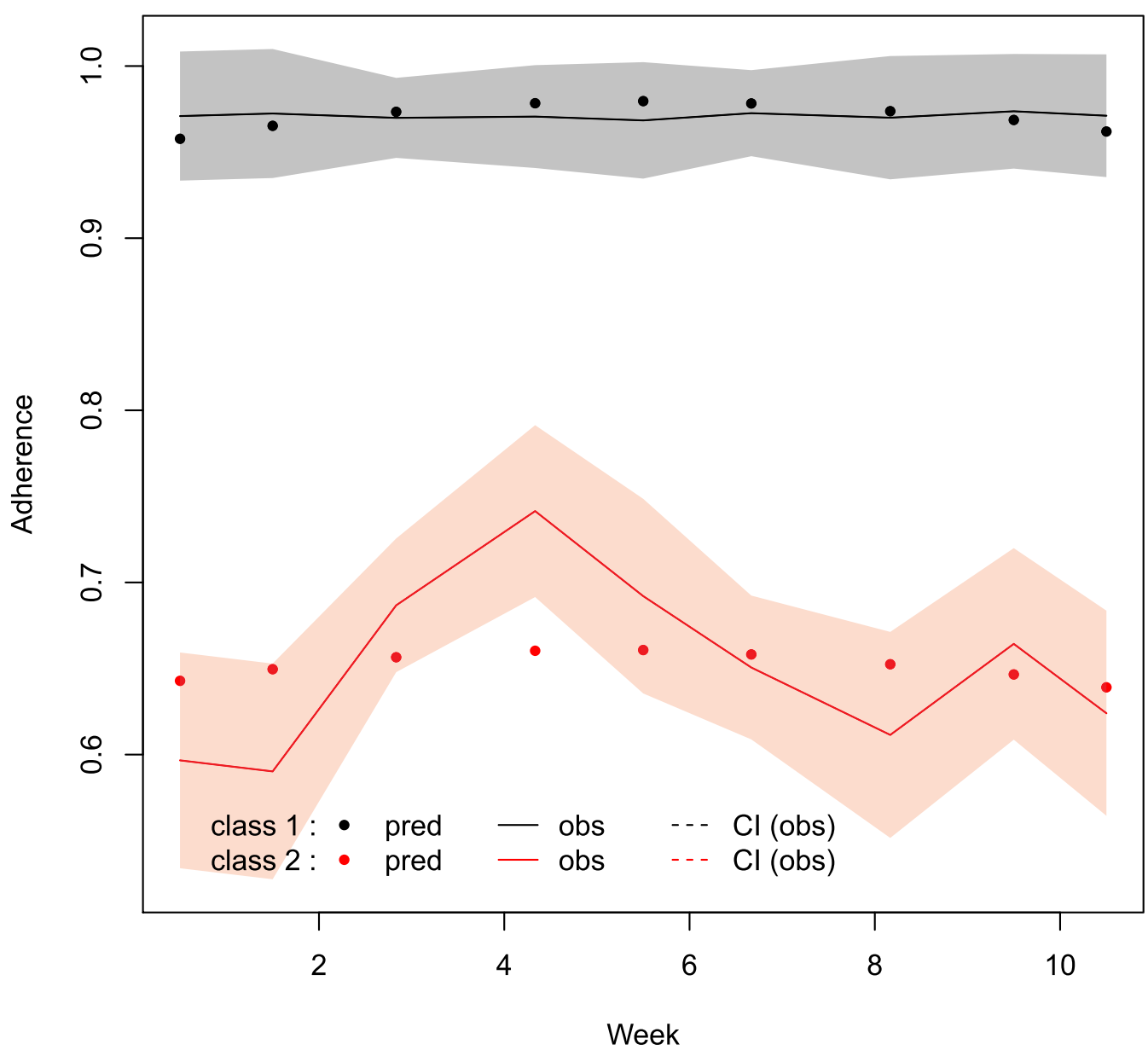

Fig. 1 Mood stabilizer adherence by week for each class. pred predicted adherence, obs observed adherence, Cl 91\% confidence interval

measures and serum levels of various psychiatric drugs (Jónsdóttir et al. 2010), and with antidepressants (Loayza et al. 2012).

Given the wide range of behaviors that may impact the initiation, implementation and persistence with treatment, understanding the specific reasons for nonadherence is needed to determine the appropriate remedy (Stirratt et al. 2018; Gellad et al. 2017). The detection of two distinct classes in the current study suggests that future research using trajectory analysis, designed to evaluate nonadherence and define membership in trajectory classes, may increase understanding of patterns of adherence in bipolar disorder.

\section{Limitations}

This analysis overestimates adherence with mood stabilizers for several reasons. By requiring 12 weeks of data, the sample analyzed was pre-selected for adherence.
Since taking one pill of a mood stabilizer was considered adherent, patients taking a lower dose than prescribed were included as adherent. The dosage timing and drug administration instructions were also not considered during the calculation. Drugs taken for general medical conditions and over the counter drugs were not included in the analysis. Complex medication regimens and requirements for dosing more than once daily are associated with decreased adherence in a wide range of chronic illness (Ingersoll and Cohen 2008; Coleman et al. 2012). In our prior research, a larger number of psychiatric medications and greater pill burden were associated with irregularity in daily dosage of mood stabilizers and single day omissions (Pilhatsch et al. 2018; Bauer et al. 2013a), but not with adherence when defined as at least one pill of a mood stabilizer a day (Bauer et al. 2010). The 12 week time period would not provide information about long-term persistence with treatment. 
Table 4 Significant differences in the classes by LCMM class $(N=273)$

\begin{tabular}{|c|c|c|c|c|c|c|c|c|}
\hline & \multicolumn{2}{|c|}{ Class 1 (adherent) } & \multicolumn{2}{|c|}{ Class 2 (less adherent) } & \multicolumn{2}{|l|}{ Total } & \multicolumn{2}{|l|}{ Test } \\
\hline & $\mathrm{N}$ & Percent & $\mathrm{N}$ & Percent & $\mathrm{N}$ & Percent & $\mathrm{X}^{2}$ Sig. & DF \\
\hline \multicolumn{9}{|l|}{ Gender } \\
\hline Male & 70 & 33.3 & 11 & 17.5 & 81 & 29.7 & 0.016 & 1 \\
\hline Female & 140 & 66.7 & 52 & 82.5 & 192 & 70.3 & & \\
\hline \multicolumn{9}{|l|}{ Diagnosis } \\
\hline BPI & 135 & 64.3 & 38 & 60.3 & 173 & 63.4 & 0.566 & 1 \\
\hline BP $\|$ & 75 & 35.7 & 25 & 39.7 & 100 & 36.6 & & \\
\hline \multicolumn{9}{|l|}{ College graduate } \\
\hline Yes & 108 & 54.8 & 33 & 55.9 & 141 & 55.1 & 0.880 & 1 \\
\hline No & 89 & 45.2 & 26 & 44.1 & 115 & 44.9 & & \\
\hline \multicolumn{9}{|l|}{ Married } \\
\hline Yes & 89 & 45.9 & 33 & 54.1 & 122 & 47.8 & 0.262 & 1 \\
\hline \multirow[t]{2}{*}{ No } & 105 & 54.1 & 28 & 45.9 & 133 & 52.2 & & \\
\hline & Mean & SD & Mean & SD & Mean & SD & F Sig. & DF \\
\hline Percent days euthymic & 68.7 & 26.0 & 49.7 & 27.4 & 64.3 & 27.5 & $<0.001$ & 1271 \\
\hline Age of onset & 22.5 & 10.3 & 21.6 & 10.5 & 22.3 & 10.3 & 0.547 & 1251 \\
\hline Age & 40.9 & 11.0 & 40.5 & 11.5 & 40.8 & 11.1 & 0.834 & 1271 \\
\hline Total number of medications ${ }^{a}$ & 2.7 & 1.4 & 3.1 & 1.5 & 2.8 & 1.4 & 0.097 & 1271 \\
\hline Total pill burden ${ }^{\mathrm{a}}$ & 6.1 & 4.2 & 6.9 & 4.3 & 6.3 & 4.3 & 0.145 & 1271 \\
\hline
\end{tabular}

a Only psychiatric drugs

There are other limitations to this study. All data were self-reported and there was no objective confirmation of the medication data. There were more females than males. Only oral drugs were included. The optimal rates to define adherence are not uniform, but vary with the pharmacokinetic and pharmacodynamic properties of the drug (Morrison et al. 2017). Adherence to specific mood stabilizers was not investigated, as drug regimens for bipolar disorder are highly customized in clinical practice (Bauer et al. 2013b). Adherence rates may be larger than one if patients take more than the prescribed dose, as noted in some newly admitted inpatients (Geretsegger et al. 2019). The least adherent patients who would not use mood charting, and those who never fill the initial prescription for a mood stabilizer were not included. In a year-long study of 195,930 new electronic prescriptions, the rate of non-filling for adults was $30.2 \%$ overall, with $27.7 \%$ for drugs classified as neuropsychiatric, and $29.5 \%$ for antidepressants (Fischer et al. 2010). ChronoRecord was not designed to evaluate the reasons for nonadherence. Many important variables were not available for analysis relating to patient attitudes, cultural issues, financial concerns, and the use of adherence tools such as pill boxes. Finally, it was not known if patients were receiving any type of psychosocial interventions for bipolar disorder.

\section{Conclusion}

In conclusion, in a sample of motivated patients who complete daily mood charting, there were two trajectories of adherence with taking at least one pill of each prescribed mood stabilizer, adherent and less adherent. About one quarter of the patients were in the less adherent class. Characteristics associated with being in the less adherent class were more time with symptoms (not euthymic), and female gender. Motivated patients may be nonadherent, and demographic characteristics may not be useful to assess individual adherence. Future research to identify longitudinal adherence trajectory patterns is needed in bipolar disorder.

\section{Acknowledgements}

None.

Authors' contributions

$\mathrm{MB}$ and TG worked on the conception and design of the study, interpreted the results and drafted the manuscript. TG performed the analyses. MA, RB, PG, WM, SM, NR, KS and PW performed data collection, and interpretation of the findings. All authors read and approved the final manuscript.

Funding

None.

Availability of data and materials

The data will not be shared or made publicly available. Informed consent for this was not sought from the study participants prior to the collection of data. 


\section{Ethics approval and consent to participate}

All participating centers obtained approval from their Institutional Review Boards and all patients gave a written informed consent to participate in this naturalistic observational non-interventional study. The data used for this paper were derived from a naturalistic observational non-interventional study, which at the time of inclusion was not registered.

\section{Consent for publication}

Consent to publish has been obtained from the participants.

\section{Competing interests}

The authors declare that they have no competing interests.

\section{Author details}

${ }^{1}$ Department of Psychiatry and Psychotherapy, Medical Faculty, University Hospital Carl Gustav Carus, Technische Universität Dresden, Fetscherstr. 74, 01307 Dresden, Germany. ${ }^{2}$ ChronoRecord Association Inc., Fullerton, CA, USA. ${ }^{3}$ Department of Psychiatry, Dalhousie University, Halifax, NS, Canada. ${ }^{4}$ Mood Disorders Center of Ottawa, University of Toronto, Toronto, Canada. ${ }^{5}$ Department of Psychiatry, University of Massachusetts, Worcester, MA, USA.

${ }^{6}$ Michigan State University College of Human Medicine, Traverse City Campus, Traverse City, MI, USA. ${ }^{7}$ Department of Psychiatry, University of California San Diego, San Diego, CA, USA. ${ }^{8}$ Department of Psychiatry and Behavioral Sciences, Stanford School of Medicine, Palo Alto, CA, USA. ${ }^{9}$ Department of Psychiatry, University of Missouri Kansas City School of Medicine, Kansas City, MO, USA. ${ }^{10}$ Department of Psychiatry and Biobehavioral Sciences, Semel Institute for Neuroscience and Human Behavior University of California Los Angeles (UCLA), Los Angeles, CA, USA.

Received: 8 May 2019 Accepted: 24 July 2019

Published online: 04 September 2019

\section{References}

Baldessarini RJ, Perry R, Pike J. Factors associated with treatment nonadherence among US bipolar disorder patients. Hum Psychopharmacol. 2008;23:95-105.

Bauer M, Grof P, Gyulai L, Rasgon N, Glenn T, Whybrow PC. Using technology to improve longitudinal studies: self-reporting with ChronoRecord in bipolar disorder. Bipolar Disord. 2004;6:67-74.

Bauer M, Wilson T, Neuhaus K, Sasse J, Pfennig A, Lewitzka U, et al. Self-reporting software for bipolar disorder: validation of ChronoRecord by patients with mania. Psychiatry Res. 2008;159:359-66.

Bauer M, Glenn T, Grof P, Marsh W, Sagduyu K, Alda M, et al. The association between concurrent psychotropic medications and self-reported adherence with taking a mood stabilizer in bipolar disorder. Hum Psychopharmacol. 2010;25:47-54

Bauer M, Glenn T, Keil M, Bauer R, Marsh W, Grof P, et al. Brief depressive symptoms in patients with bipolar disorder: analysis of long-term self-reported data. Aust N Z J Psychiatry. 2012;46:1068-78.

Bauer M, Glenn T, Alda M, Sagduyu K, Marsh W, Grof P, et al. Regularity in daily mood stabilizer dosage taken by patients with bipolar disorder. Pharmacopsychiatry. 2013a;46:163-8.

Bauer M, Glenn T, Alda M, Sagduyu K, Marsh W, Grof P, et al. Drug treatment patterns in bipolar disorder: analysis of long-term self-reported data. Int J Bipolar Disord. 2013b;1:5.

Belzeaux R, Correard N, Boyer L, Etain B, Loftus J, Bellivier F, et al. Depressive residual symptoms are associated with lower adherence to medication in bipolar patients without substance use disorder: results from the FACEBD cohort. J Affect Disord. 2013;151:1009-15.

Belzeaux R, Boyer L, Mazzola-Pomietto P, Michel P, Correard N, Aubin V, et al. Adherence to medication is associated with non-planning impulsivity in euthymic bipolar disorder patients. J Affect Disord. 2015;184:60-6.

Blalock DV, Bosworth HB, Reeve BB, Voils Cl. Co-occurring reasons for medication nonadherence within subgroups of patients with hyperlipidemia. J Behav Med. 2019;42:291-9.

Coleman Cl, Limone B, Sobieraj DM, Lee S, Roberts MS, Kaur R, et al. Dosing frequency and medication adherence in chronic disease. J Manag Care Pharm. 2012;18:527-39.
Colom F, Vieta E, Tacchi MJ, Sánchez-Moreno J, Scott J. Identifying and improving non-adherence in bipolar disorders. Bipolar Disord. 2005;7(Suppl 5):24-31.

Copeland LA, Miller AL, Welsh DE, McCarthy JF, Zeber JE, Kilbourne AM. Clinical and demographic factors associated with homelessness and incarceration among VA patients with bipolar disorder. Am J Public Health. 2009;99:871-7.

De las Cuevas C, Peñate W, Sanz EJ. Psychiatric outpatients' self-reported adherence versus psychiatrists'impressions on adherence in affective disorders. Hum Psychopharmacol. 2013;28:142-50.

de Vries McClintock HF, Morales KH, Small DS, Bogner HR. Patterns of adherence to oral hypoglycemic agents and glucose control among primary care patients with type 2 diabetes. Behav Med. 2016;42:63-71.

Dell'Osso L, Pini S, Cassano GB, Mastrocinque C, Seckinger RA, Saettoni M, et al. Insight into illness in patients with mania, mixed mania, bipolar depression and major depression with psychotic features. Bipolar Disord. 2002;4:315-22.

Di Matteo MR. Variations in patients' adherence to medical recommendations: a quantitative review of 50 years of research. Med Care. 2004;42:200-9.

Eaddy M, Grogg A, Locklear J. Assessment of compliance with antipsychotic treatment and resource utilization in a Medicaid population. Clin Ther. 2005;27:263-72.

Fischer MA, Stedman MR, Lii J, Vogeli C, Shrank WH, Brookhart MA, et al. Primary medication non-adherence: analysis of 195,930 electronic prescriptions. J Gen Intern Med. 2010;25:284-90.

Frank E, Swartz HA, Kupfer DJ. Interpersonal and social rhythm therapy: managing the chaos of bipolar disorder. Biol Psychiatry. 2000;48:593-604.

Franklin JM, Shrank WH, Lii J, Krumme AK, Matlin OS, Brennan TA, et al. Observing versus predicting: initial patterns of filling predict long-term adherence more accurately than high-dimensional modeling techniques. Health Serv Res. 2016;51:220-39.

Franks M, Macritchie KA, Mahmood T, Young AH. Bouncing back: is the bipolar rebound phenomenon peculiar to lithium? A retrospective naturalistic study. J Psychopharmacol. 2008;22:452-6.

Fredericksen RJ, Gibbons L, Brown S, Edwards TC, Yang FM, Fitzsimmons E, et al Medication understanding among patients living with multiple chronic conditions: implications for patient-reported measures of adherence. Res Soc Adm Pharm. 2018;14:540-4.

Garber MC, Nau DP, Erickson SR, Aikens JE, Lawrence JB. The concordance of self-report with other measures of medication adherence: a summary of the literature. Med Care. 2004;42:649-52.

García S, Martínez-Cengotitabengoa M, López-Zurbano S, Zorrilla I, López P, Vieta E, et al. Adherence to antipsychotic medication in bipolar disorder and schizophrenic patients: a systematic review. J Clin Psychopharmacol. 2016;36:355-71.

Gellad WF, Thorpe CT, Steiner JF, Voils Cl. The myths of medication adherence. Pharmacoepidemiol Drug Saf. 2017;26:1437-41.

Geretsegger C, Pichler EM, Gimpl K, Aichhorn W, Stelzig R, Grabher-Stoeffler $\mathrm{G}$, et al. Non-adherence to psychotropic medication assessed by plasma level in newly admitted psychiatric patients: prevalence before acute admission. Psychiatry Clin Neurosci. 2019;73:175-8.

Gianfrancesco FD, Rajagopalan K, Sajatovic M, Wang RH. Treatment adherence among patients with bipolar or manic disorder taking atypical and typical antipsychotics. J Clin Psychiatry. 2006;67:222-32.

Gianfrancesco FD, Sajatovic M, Rajagopalan K, Wang RH. Antipsychotic treatment adherence and associated mental health care use among individuals with bipolar disorder. Clin Ther. 2008;30:1358-74.

Gonzalez-Pinto A, Mosquera F, Alonso M, López P, Ramírez F, Vieta E, et al. Suicidal risk in bipolar I disorder patients and adherence to long-term lithium treatment. Bipolar Disord. 2006;8:618-24.

Greene M, Paladini L, Lemmer T, Piedade A, Touya M, Clark O. Systematic literature review on patterns of pharmacological treatment and adherence among patients with bipolar disorder type I in the USA. Neuropsychiatr Dis Treat. 2018;14:1545-59.

Greenley RN, Karazsia B, Schurman JV, Gumidyala AP, Nguyen EU, Thomason MM, et al. Trajectories of oral medication adherence in youth with inflammatory bowel disease. Health Psychol. 2015;34:514-21.

Gutiérrez-Rojas L, Jurado D, Martínez-Ortega JM, Gurpegui M. Poor adherence to treatment associated with a high recurrence in a bipolar disorder outpatient sample. J Affect Disord. 2010;127:77-83. 
Hassan M, Lage MJ. Risk of rehospitalization among bipolar disorder patients who are nonadherent to antipsychotic therapy after hospital discharge. Am J Health Syst Pharm. 2009;66:358-65.

Hodgkin D, Stewart MT, Merrick EL, Pogue YZ, Reilly-Harrington NA, Sylvia $L G$, et al. Prevalence and predictors of physician recommendations for medication adjustment in bipolar disorder treatment. J Affect Disord. 2018;238:666-73.

Hommel KA, McGrady ME, Peugh J, Zacur G, Loreaux K, Saeed S, et al. Longitudinal patterns of medication nonadherence and associated health care costs. Inflamm Bowel Dis. 2017;23:1577-83.

Hong J, Reed C, Novick D, Haro JM, Aguado J. Clinical and economic consequences of medication non-adherence in the treatment of patients with a manic/mixed episode of bipolar disorder: results from the European Mania in Bipolar Longitudinal Evaluation of Medication (EMBLEM) study. Psychiatry Res. 2011;190:110-4.

Ingersoll KS, Cohen J. The impact of medication regimen factors on adherence to chronic treatment: a review of literature. J Behav Med. 2008;31:213-24.

Jawad I, Watson S, Haddad PM, Talbot PS, McAllister-Williams RH. Medication nonadherence in bipolar disorder: a narrative review. Ther Adv Psychopharmacol. 2018;8:349-63.

Jónsdóttir H, Opjordsmoen S, Birkenaes AB, Engh JA, Ringen PA, Vaskinn A, et al. Medication adherence in outpatients with severe mental disorders: relation between self-reports and serum level. J Clin Psychopharmacol. 2010;30:169-75

Jung T, Wickrama KAS. An introduction to latent class growth analysis and growth mixture modeling. Soc Personal Psychol Compass. 2008;2:302-17.

Kessing LV, Søndergård L, Kvist K, Andersen PK. Adherence to lithium in naturalistic settings: results from a nationwide pharmacoepidemiological study. Bipolar Disord. 2007;9:730-6.

Leclerc E, Mansur RB, Brietzke E. Determinants of adherence to treatment in bipolar disorder: a comprehensive review. J Affect Disord. 2013;149:247-52.

Lehmann A, Aslani P, Ahmed R, Celio J, Gauchet A, Bedouch P, et al. Assessing medication adherence: options to consider. Int J Clin Pharm. 2014:36:55-69.

Lennon H, Kelly S, Sperrin M, Buchan I, Cross AJ, Leitzmann M, et al. Framework to construct and interpret latent class trajectory modelling. BMJ Open. 2018;8:e020683.

Levin JB, Sams J, Tatsuoka C, Cassidy KA, Sajatovic M. Use of automated medication adherence monitoring in bipolar disorder research: pitfalls, pragmatics, and possibilities. Ther Adv Psychopharmacol. 2015;5:76-87.

Levin JB, Krivenko A, Howland M, Schlachet R, Sajatovic M. Medication adherence in patients with bipolar disorder: a comprehensive review. CNS Drugs. 2016;30:819-35.

Loayza N, Crettol S, Riquier F, Eap CB. Adherence to antidepressant treatment: what the doctor thinks and what the patient says. Pharmacopsychiatry. 2012:45:204-7.

Lopez LV, Shaikh A, Merson J, Greenberg J, Suckow RF, Kane JM. Accuracy of clinician assessments of medication status in the emergency setting: a comparison of clinician assessment of antipsychotic usage and plasma level determination. J Clin Psychopharmacol. 2017;37:310-4.

McQuaid EL, Landier W. Cultural issues in medication adherence: disparities and directions. J Gen Intern Med. 2018;33:200-6.

Melo MCA, Abreu RLC, Linhares Neto VB, de Bruin PFC, de Bruin VMS. Chronotype and circadian rhythm in bipolar disorder: a systematic review. Sleep Med Rev. 2017;34:46-58.

Monnette A, Zhang Y, Shao H, Shi L. Concordance of adherence measurement using self-reported adherence questionnaires and medication monitoring devices: an updated review. Pharmacoeconomics. 2018;36:17-27.

Morrison A, Stauffer ME, Kaufman AS. Relationship between adherence rate threshold and drug 'forgiveness'. Clin Pharmacokinet. 2017;56:1435-40.

Murru A, Pacchiarotti I, Amann BL, Nivoli AM, Vieta E, Colom F. Treatment adherence in bipolar I and schizoaffective disorder, bipolar type. J Affect Disord. 2013;151:1003-8.

Nagin DS, Odgers CL. Group-based trajectory modeling in clinical research. Annu Rev Clin Psychol. 2010;6:109-38.

Osterberg L, Blaschke T. Adherence to medication. N Engl J Med. 2005:353:487-97.

Pilhatsch M, Glenn T, Rasgon N, Alda M, Sagduyu K, Grof P, et al. Regularity of self-reported daily dosage of mood stabilizers and antipsychotics in patients with bipolar disorder. Int J Bipolar Disord. 2018;6:10.
Pompili M, Serafini G, Del Casale A, Rigucci S, Innamorati M, Girardi P, et al. Improving adherence in mood disorders: the struggle against relapse, recurrence and suicide risk. Expert Rev Neurother. 2009;9:985-1004.

Proust-Lima C, Philipps V, Liquet B. Estimation of extended mixed models using latent classes and latent processes: the R Package $1 \mathrm{cmm}$. J Stat Softw. 2017;78:1-56.

Robertson AG, Swanson JW, Van Dorn RA, Swartz MS. Treatment participation and medication adherence: effects on criminal justice costs of persons with mental illness. Psychiatr Serv. 2014;65:1189-91.

Sajatovic M, Velligan DI, Weiden PJ, Valenstein MA, Ogedegbe G. Measurement of psychiatric treatment adherence. J Psychosom Res. 2010;69:591-9.

Sawada N, Uchida H, Watanabe K, Kikuchi T, Suzuki T, Kashima H, et al. How successful are physicians in eliciting the truth from their patients? A large-scale Internet survey from patients' perspectives. J Clin Psychiatry. 2012;73:311-7.

Schuepbach D, Novick D, Haro JM, Reed C, Boeker H, Noda S, et al. Determinants of voluntary vs. involuntary admission in bipolar disorder and the impact of adherence. Pharmacopsychiatry. 2008:41:29-36.

Scott J, Pope M. Nonadherence with mood stabilizers: prevalence and predictors. J Clin Psychiatry. 2002;63:384-90.

Shi L, Liu J, Koleva Y, Fonseca V, Kalsekar A, Pawaskar M. Concordance of adherence measurement using self-reported adherence questionnaires and medication monitoring devices. Pharmacoeconomics. 2010;28:1097-107.

Stavropoulou C. Non-adherence to medication and doctor-patient relationship: evidence from a European survey. Patient Educ Couns. 2011;83:7-13.

Steiner JF. Rethinking adherence. Ann Intern Med. 2012;157:580-5.

Steiner JF, Ho PM, Beaty BL, Dickinson LM, Hanratty R, Zeng C, et al. Sociodemographic and clinical characteristics are not clinically useful predictors of refill adherence in patients with hypertension. Circ Cardiovasc Qual Outcomes. 2009;2:451-7.

Stephenson JJ, Tunceli O, Gu T, Eisenberg D, Panish J, Crivera C, et al. Adherence to oral second-generation antipsychotic medications in patients with schizophrenia and bipolar disorder: physicians' perceptions of adherence vs. pharmacy claims. Int J Clin Pract. 2012;66:565-73.

Stirratt MJ, Dunbar-Jacob J, Crane HM, Simoni JM, Czajkowski S, Hilliard ME, et al. Self-report measures of medication adherence behavior: recommendations on optimal use. Transl Behav Med. 2015;5:470-82.

Stirratt MJ, Curtis JR, Danila MI, Hansen R, Miller MJ, Gakumo CA. Advancing the science and practice of medication adherence. J Gen Intern Med. 2018;33:216-22.

Svarstad BL, Shireman TI, Sweeney JK. Using drug claims data to assess the relationship of medication adherence with hospitalization and costs. Psychiatr Serv. 2001;52:805-11.

Swann AC, Steinberg JL, Lijffijt M, Moeller FG. Impulsivity: differential relationship to depression and mania in bipolar disorder. J Affect Disord. 2008:106:241-8.

Van De Schoot R, Sijbrandij M, Winter SD, Depaoli S, Vermunt JK. The GRoLTSchecklist: guidelines for reporting on latent trajectory studies. Struct Equ Model. 2017;24:451-67.

Velligan DI, Weiden PJ, Sajatovic M, Scott J, Carpenter D, Ross R, et al. The expert consensus guideline series: adherence problems in patients with serious and persistent mental illness. J Clin Psychiatry. 2009;70(Suppl 4): $1-46$.

Vieta E, Azorin JM, Bauer M, Frangou S, Perugi G, Martinez G, et al. Psychiatrists' perceptions of potential reasons for non- and partial adherence to medication: results of a survey in bipolar disorder from eight European countries. J Affect Disord. 2012;143:125-30.

Vrijens B, De Geest S, Hughes DA, Przemyslaw K, Demonceau J, Ruppar T, et al. A new taxonomy for describing and defining adherence to medications. Br J Clin Pharmacol. 2012;73:691-705.

\section{Publisher's Note}

Springer Nature remains neutral with regard to jurisdictional claims in published maps and institutional affiliations. 